\title{
İnşaat Mühendisliği Malzeme Testi Uygulamaları İçin Fotogrametrik Bir Sistem Tasarımı
}

\author{
Ferruh YILMAZTÜRK ${ }^{*}$, Niyazi U.TERZI'² \\ ${ }^{1}$ AksarayÜniversitesi, Mühendislik Fakültesi, Harita Mühendisliği Bölümü, Aksaray \\ (fyilmazturk@gmail.com) ORCID ID 0000-0002-8347-664X \\ ${ }^{2}$ Aksaray Üniversitesi, Mühendislik Fakültesi, İnşaat Mühendisliği Bölümü, Aksaray \\ (niyaziterzi@gmail.com) ORCID ID 0000-0003-1787-5674
}

$\ddot{\mathbf{O} z}$

$\mathrm{Bu}$ çalışmada, statik ya da yarı statik yükleme deneylerinde yapı elemanlarının deformasyon davranışlarını gerçek zamana yakın $(<1 \mathrm{sn})$ belirleyebilmek için geliştirilen fotogrametrik bir sistem anlatılmıştır. Sistem yazılım ve donanım olmak üzere iki bileşenden oluşmaktadır. Donanım bileşeni 3 video kameralı görüntü elde etme sistemini, yazılım bileşeni de elde edilen görüntülerin fotogrametrik olarak değerlendirilip konum bilgisinin üretilmesini içerir. Sistemin ölçme işlemi, iki temel işlem adımından oluşur. İlk işlem adımı, üç kameraya ait iç ve dış yöneltme parametrelerinin belirlendiği sistem kalibrasyonunu içerir. İkinci işlem adımı ise hesaplanan kalibrasyon parametreleri kullanılarak tanımlanan zaman aralıklarında ya da her bir yükleme uygulamasından sonra yapı elemanı üzerindeki işaretli noktaların 3B koordinatlarının hesaplanması ilkesine dayanır. Test amacıyla, sistem gömülü esnek boruların ve çelik bir kirişin yük testi deneylerinde kullanılmıştır. Deneylerde inşaat mühendisliği klasik ölçme aletleri de kullanılmış ve her iki ölçme sisteminden elde edilen sonuçların kıyaslaması, fotogrametrik sistemin doğru ve güvenilir bir ölçme sistemi olduğunu göstermiştir.

Anahtar Kelimeler: Yakın resim fotogrametrisi, kamera kalibrasyonu, yer değiştirme ölçmeleri.

\section{A Photogrammetric System Design for Civil Engineering Materials Testing Applications}

\begin{abstract}
In this study, a photogrammetric system developed to determine near real time $(<1 \mathrm{sec})$ the displacement or deformations of structural elements in static load tests is described. The system consists of two components that are software and hardware. Basically, the hardware component includes online image acquisition system with three CCD cameras, whereas the software component contains photogrammetric processing of obtained image data. The measurement process of the system consists of two basic process steps. The first process step involves the system calibration, in which the parameters of the interior and exterior orientation of the three cameras are determined. The second process step is based on the calculation of the 3D coordinates of the marked points on the structural member at time intervals defined or after each loading application using the calculated calibration parameters. For testing purposes, the system was used in load test of the buried flexible pipes and a steel beam. In these experiments, the classical measurement tools of civil engineering were also used and the comparison of results obtained from both measurement systems indicated that photogrammetric system is a reliable and accurate measurement system.
\end{abstract}

Keywords: Close Range Photogrammetry, Camera Calibration, Displacement Measurements

* Sorumlu Yazar 


\section{GİRIŞ}

Farklı yükleme koşulları altında yapı elemanlarının test edilmesi standart bir mühendislik uygulamasıdır. Geometrik ölçmeler, teorilerin ya da mekanik modellerin doğrulanması için veya test cisminin davranışının belirlenmesi için uygulanır. $\mathrm{Bu}$ genellikle statik, yarı statik ya da dinamik kısa ve uzun süreli yük deneyleri ile laboratuar koşullarında gerçekleştirilir. Yük testleri boyunca, deformasyon, gerilme ve yer değiştirme gibi etki ve parametrelerin belirlenmesi amaçlanır.

Malzeme testi uygulamalarında, yer değiştirme ölçmeleri genel olarak gerilimölçerler (strain gauges) ya da doğrusal değişimli fark transformatörleri (LVDT- Lineer Variable Differential Transducer) gibi klasik ölçme araçları ile yapılır. Klasik ölçme sistemleri yüksek geometrik doğruluk ve güvenilirlikle eş zamanlı sonuçlar verirler. En önemli dezavantajları ise noktasal ve tek boyutlu ölçme yeteneklerinin olmasıdır. Söz konusu teknikler, cisim yüzeyi üzerindeki çok sayıda ölçme noktasının gerekli olduğu ya da komple yüzey ölçmeleri için uygun değildir.

$\mathrm{Bu}$ durumda, dijital fotogrametrik teknikler, güçlü ve esnek bir ölçme sisteminin tasarımı için uygun bir seçenek olarak karşımıza çıkar. Farklı zamanlarda ya da farklı yükleme koşulları altında, yapı üzerinde, istenen noktaların 3 boyutlu koordinatları fotogrametrik teknikler kullanılarak hesaplanır ve noktaların hareketinin büyüklügünü ve yönünü veren yer değiştirmeler, koordinat değişimlerinden belirlenebilir. Malzeme testi uygulamalarında dijital fotogrametrinin kullanılması, kameranın görüş alanında çok sayıdaki noktadaki deformasyon ya da yer değiştirmelerin eş zamanlı olarak ölçülmesine izin verir. Veri işleme yüksek derecede otomatik ve hizlı olabilmektedir (Maas ve Hampel 2006).

Literatürde, yüksek mukavemete sahip beton kolonların yük testleri (Woodhouse ve diğ. 1999), çelik bir kirişin termal deformasyonlarının izlenmesi (Fraser ve Riedel 2000), güçlendirilmiş beton numune üzerindeki çatlakların dinamik yük testi boyunca davranışlarının belirlenmesi (Hampel ve Maas 2003), farklı yol kaplamalarının dinamik yük altında davranışlarının belirlenmesi (Maas ve Hampel 2006; Mills ve diğ. 2001), kontrollü yük altında beton kirişin düşey hareketlerinin belirlenmesi (Whiteman ve Lichti 2002), beton kirişlerin yük altında iki boyutlu deformasyonlarının belirlenmesi (Psaltis ve Ionnadis 2006) ve kompleks binaların yapısal sapmalarının ölçmesi (Fraser ve diğ. 2003), bağlantılı çelik kirişlerin ve bağlantı yerlerinin yük altındaki davranışlarının izlenmesi (Valença ve diğ, 2012) gibi fotogrametrik tekniklerin kullanıldığ 1 birçok farklı inşaat mühendisliği malzeme testi uygulamas1 vardır.

Bir test cismi üzerindeki işaretlenmiş noktaların hareketi ve mutlak koordinatlarının ölçmesi ticari fotogrametrik yazılımlar tarafindan çözülürken, standart olmayan izleme uygulamaları ya da gerçek zamanlı veya gerçek zamana yakın sonuçlar isteyen uygulamalar için bu amaca yönelik özel yazılım araçlarının geliştirilmesi gerekmektedir.

$\mathrm{Bu}$ çalışmada, yük testleri süresince yap1 bileşeni üzerindeki işaretli noktaların 3B koordinatlarını gerçek zamana yakın $(<1$ sn $)$ ölçmek için geliştirilen fotogrametrik bir sistem anlatılmıştır. Borland $\mathrm{C}++$ Builder programlama dili kullanılarak geliştirilen yazılım bileşeninde, video kameralardan görüntü alma, tanımlanmış özel hedefi görüntülerde arama ve bulunan hedefleri piksel altı doğrulukta ölçme, görüntü eşleme, demet dengelemesi, self-kalibrasyon gibi birçok fonksiyon sunulmuştur. Sistemin donanım bileşeni ise, bir bilgisayar, üç adet Basler A302fc video kamera, PCI IEEE 1394 arabirim kart1, bağlantı kabloları ve kalibrasyon cismini içermektedir.

Tasarlanan sistem, çelik bir kirişin yük testi deneylerinde ve gömülü esnek boruların yük altındaki davranışlarının belirlenmesinde kullanılmıştır. Deneylerde ölçmeler, yük uygulamasından sonra gerçekleştirilmiştir. Fotogrametrik sistemle, bu deneylerin her bir ölçme oturumu için mm düzeyi altında cisim nokta prezisyonları elde edilmiștir. Gömülü esnek boruların yük testi deneylerinde klasik ölçme aracı LVDT'ler de kullanılmıştır. Geliştirilen fotogrametrik sistemle LVDT'lerden elde edilen ölçme sonuçları 
kıyaslanmış ve fotogrametrik sistemin doğru ve güvenilir bir ölçme sistemi olduğu görülmüştür.

Makalenin sonraki bölümlerinde, fotogrametrik ölçme sisteminin tasarımı anlatılacaktır. Donanım bileşeni ve kullanılan algoritmalar verilecek ve sistemin ölçme işlemini nasıl gerçekleştirdiğinden bahsedilecektir. Son bölümdeyse sistemi test etmek için gerçekleştirilen yük deneyleri ve deney sonuçları anlatılacaktır.

\section{GÖRÜNTÜLERINN ELDE EDILMESİ VE KAMERA KALIBRASYONU}

Şekil 1, kullanılan görüntü elde etme sistemini göstermektedir. Sistem, bir tripod üzerine monte edilebilen alüminyum bir parça üzerinde farklı konumlara yerleştirilmiş üç adet alan taramalı Basler A302fs kamerasindan oluşmaktadır. Maksimum 780x582 piksel çözünürlüğe sahip olan kameraların bir pikselinin boyutu $8.3 \mu \mathrm{m}$ 'dir. Kenarlardaki kameralarda $16 \mathrm{~mm}$ sabit odak uzaklıklı mercek, ortada bulunan üçüncü kamerada ise minimumu $12.5 \mathrm{~mm}$ ve maksimumu $70 \mathrm{~mm}$ olmak üzere değişken odak uzaklıklı mercek kullanılmıştır. Kamera bilgisayar bağlantıları, görüntülerin dijital iletimine izin veren IEEE1394 ara yüzü yoluyla sağlanmıştır.

Kamera kalibrasyon ve yöneltme işlemleri görüntülerden hassas ve güvenilir 3B metrik bilgi elde etmek için gerekli bir önkoşuldur. $\mathrm{Bu}$ amaçla her bir yük deneyinden önce üç kameralı sistem self-kalibrasyon demet dengelemesi yöntemiyle kalibre edilmiştir. Yöntemin matematik modeli, genişletilmiş kolinearite eşitliklerine dayanır.

Ek parametrelerin bir setinin fonksiyonları olan resim koordinat düzeltme terimleri, doğada fiziksel olan doğrusallık koşulunun ideal geometrisinden olan sapmaları modeller. Geliştirilen yazılımda, iç yöneltme elemanları $(\mathrm{x} 0, \mathrm{y} 0, \mathrm{c})$, mercek distorsiyon katsayılar1 (k1, $\mathrm{k} 2, \mathrm{k} 3$ ve p1, p2) ve resim koordinat eksenleri arasındaki ölçekleme farkından ya da resim koordinat eksenlerinin birbirine dik olmamasindan kaynaklanan düzeltme terimlerini içeren $(\mathrm{b} 1, \mathrm{~b} 2)$ standart 10 terimli fiziksel kalibrasyon modeli kullanılmıştır. (Fraser 1997). Kalibrasyon işlemin sonucunda, kameraların konum, yöneltme parametreleri ve ek parametreler belirlenir.

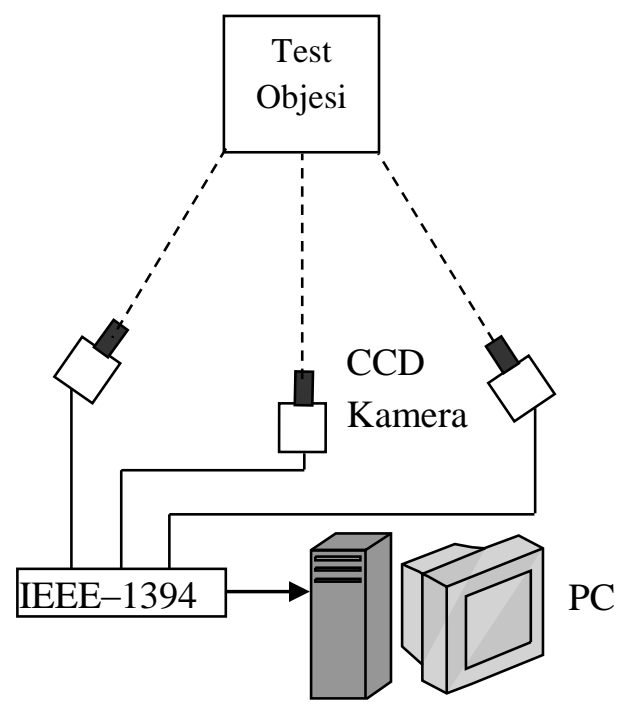

Şekil 1. Görüntü elde etme sistemi

\section{3. ÖLÇME İŞLEMI}

Kameraların kalibrasyon ve yöneltme parametreleri belirlendikten sonra, test cisminin yük altındaki davranışının izlemesine geçilebilir. Siyah arka plan üzerinde beyaz benek biçiminde olan hedef işaretleri test cisminin yüzeyi üzerine yerleştirilmiştir. Yer değiştirmeler, her bir yüklemeden sonra bu işaretli noktaların hareketinin doğrultusu ve büyüklügüyle belirlenir. Yük uygulamadan önce bu noktalara ait bir başlangıç ölçmesi yapılır. Başlangıç ölçmesinde, çoklu görüntülerde karşıllklı hedef noktaları belirlenir ve bu noktaların 3B cisim koordinatları kalibrasyon işleminin sonuçları kullanılarak uzaysal ileriden kestirme dengelemesiyle hesaplanır. Kameralar ölçme işlemi süresince sabit konumda kalırlar.

\subsection{Fotogrametrik Nokta Ölçümü}

Hedef görüntülerinin piksel altı doğrulukta konumlarının hesaplanması, hedef tanıma ve konum belirleme olmak üzere iki aşamada gerçekleştirilir. Hedef görüntülerinin tanınması, görüntü üzerinde hassas bir şekilde konumunun belirlenebilmesi için gereklidir. Hedef konumunun belirlenmesi genellikle ikinci bir aşamadır. 
Geliştirilen yazılımda, hedef tanıma kriteri olarak çapraz korelasyonla görüntü eşleştirme yöntemi kullanılmıştır. Bu tip eşleştirmede temel düşünce, aynı olayı tanımlayan iki görüntü penceresindeki gri düzey değerleri arasında hesaplanan korelasyon katsayılarının en büyüğü ile benzerliği bulmaktır. $\mathrm{Bu}$ pencerelerden ilki şablon pencere diye adlandırılan referans görüntü, diğeri ise bu şablon pencerenin çakıştırılacağı arama penceresidir (Krauss 1997)

Korelasyon katsayıs1 (r) her iki görüntüdeki gri düzey değerler (g1 ve g2) arasındaki kovaryanstan $(\sigma 12)$ ve görüntülerin gri değerlerinin standart sapmalarından ( $\sigma 1$ ve $\sigma 2)$ hesaplanir.

$r=\frac{\sigma_{12}}{\sigma_{1} \cdot \sigma_{2}}=\frac{\sum\left(g_{1}-\bar{g}_{1}\right)\left(g_{2}-\bar{g}_{2}\right)}{\sqrt{\left(g_{1}-\bar{g}_{1}\right)^{2}\left(g_{2}-\bar{g}_{2}\right)^{2}}}$

Yazılımin hedef belirleme algoritmas1 aşağıdaki gibi çalışır. Test cisminin her hangi bir görüntüsünden elde edilebilen şablon pencere, geçerli görüntü üzerinde piksel piksel kaydırılır ve her konumdaki korelasyon katsayısı hesaplanır. Şekil 2, geliştirilen yazılımda hedef görüntü ve hedef parametreleri girişini göstermektedir. Hesaplanan değer hedef parametrelerinde tanımlanan minimum korelasyon katsayısından büyükse söz konusu konumda hedef görüntüsü olabileceği düşünülür.

Sonraki aşama, geçerli görüntü üzerinde hedef görüntünün piksel altı doğrulukta konumunun belirlenmesi için ikinci bir hesap işleminin uygulanmasıdır. $\mathrm{Bu}$ hesaplama, ön işlem aşaması ve gerçek merkez hesabı olmak üzere iki aşamada gerçekleştirilir.

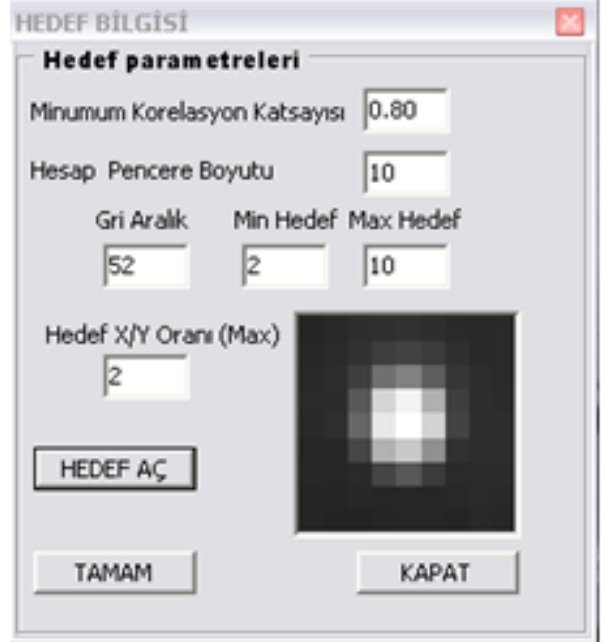

Şekil 2. Yazılımda hedef görüntü parametreleri

\subsection{1. Ön işleme}

Hedef konum belirleme işleminde ilk adım, pikselleri hedef bilgisi ya da artalan gürültüsü olarak sınıflandıran bir eşikleme işlemidir. Eşikleme işleminde Şekil 3'de görüleceği gibi hedefin yoğunluk görüntüsünden belirli bir artalan yoğunluğu çıkarılır.

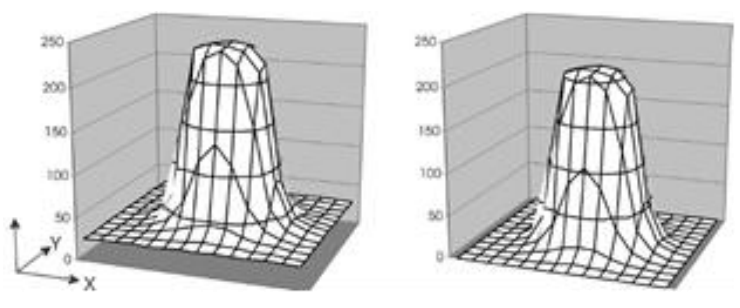

Şekil 3. Artalan eşiklemeden sonra hedef görüntü

Eşik çıkarma, her dijital görüntüde artalan gürültüsünün olacağı fikrine dayanır. İstenmeyen artalan aydınlatması, düşük düzeyli elektronik etkiler ve görüntü kayıt ortamından ileri gelen yeniden örnekleme etkileri, artalan gürültüsüne neden olur. Dolayısıyla hedef görüntü sinyalini ayırmak için artalan gürültüsünün kaldırılması gerekir (Shortis ve dĭ̆. 1994).

Eşik değerini hesaplamak için yazılımda kullanılan yaklaşım, kenar piksellerin gri değerlerinin dağılımının istatistiksel analizini 
gerektirir. $\mathrm{Bu}$ amaçla ilk olarak yazılımda hedef görüntüsü parametrelerinden girilen hesap penceresi boyutlarında ve korelasyon hesabı kullanılarak elde edilen hedef görüntü merkezinin piksel koordinatlarını ortalayan hesap penceresi görüntüsü geçerli görüntüden çıkarılır. Hedef parametrelerinde tanımlanan hedef görüntünün minimum gri değer aralığına bağlı olarak beklenen maksimum yoğunluk değeri için kritik bir değer belirlendikten sonra piksel gri değerlerinin ortalama ve standart sapma değerleri kullanılarak eşik değer hesaplanır. İstatistiksel metot, global bir limit ayarlamasını, pencerenin hedef görüntü üzerinde merkezlendirilmesini ve iteratif bir eşik değer hesabını gerektirir. Bu önlemler olmadan, örneğin pencere kenarına giren başka bir hedef görüntünün etkisi altında yanlış eşik değerleri hesaplanabilir. Şekil 4, bir hedef görüntüye ait eşikleme işlemi sonrasında elde edilen gri değerleri göstermektedir.

\subsubsection{Hedef Görüntünün Ana Görüntü Bölgesinin Test Edilmesi}

Yüksek kontrastlı hedefler için eșik değer belirleme algoritmalarının hepsi, aykırı pikseller riskini göze almalıdır. Böyle pikseller, eşik değerinin üstünde yoğunluk değerlerine sahiptir fakat hedef görüntünün ana görüntü bölgesine ait bir parça değildir. Konu dışı artalan detaylar ya da diğer hedef görüntülerin geçerli pencereye girmesi aykırı piksellere neden olur. Aykırı piksellerin kaldırılması, pencere merkezinin en azından yaklaşık olarak bilinen hedef görüntü üzerinde merkezlendirilmesi düşüncesine dayanır. İlk konum çapraz korelasyonla hesaplanmıştır. Aykırılığın kaldırılması işlemi hedef ana görüntü bölgesinin kenarlarının belirlenmesiyle kontrol edilir. Kenar belirleme kriteri, eşik değerin altındaki piksel yoğunluğunun ilk değeridir. Pencere boyutunun yeterince büyük olduğu varsayımı altında pikseller hedef görüntü merkezinden dışa doğru taranarak hedef görüntü kenarı belirlenir. Görüntü kenarı belirlenince, pencere kenarına doğru karşılaşılan bütün sonraki gelen pikseller hedefin ana görüntüsüne ait olmayan pikseller olarak düşünülür ve yoğunlukları sıfıra ayarlanır. Aykırılık için tarama, görüntü tarama satırları boyunca ve karşısında olmak üzere iki dik doğrultuda yerine getirilir.

\begin{tabular}{lllllllllll|l}
0 & 0 & 0 & 0 & 0 & 0 & 0 & 0 & 0 & 0 \\
0 & 0 & 0 & 0 & 0 & 2 & 0 & 0 & 0 & 0 \\
0 & 0 & 0 & 2 & 10 & 12 & 8 & 0 & 0 & 0 \\
0 & 0 & 0 & 9 & 29 & 40 & 28 & 9 & 0 & 0 \\
0 & 0 & 0 & 19 & 91 & 130 & 86 & 19 & 0 & 0 \\
0 & 0 & 2 & 47 & 165 & 196 & 149 & 31 & 0 & 0 \\
0 & 0 & 0 & 42 & 148 & 171 & 132 & 21 & 0 & 0 \\
0 & 0 & 0 & 9 & 67 & 90 & 45 & 0 & 0 & 0 \\
0 & 0 & 0 & 0 & 3 & 4 & 0 & 0 & 0 & 0 \\
0 & 0 & 0 & 0 & 0 & 0 & 0 & 0 & 0 & 0 \\
0 & 0 & 0 & 0 & 0 & 0 & 0 & 0 & 0 & 0
\end{tabular}

Şekil 4. Eşikleme işlemi sonrası hedef görüntünün gri değerleri

\subsubsection{Geometrik Test}

Hedef görüntünün piksel altı konumunun belirlenmesinden önce hedef olmayan bölgelerin elimine edilmesi gerekir. Fakat hedef ve hedef olmayan bölgeleri 100\% ayırt etmeyi amaçlayan stratejileri oluşturmak hem çok zordur hem de oldukça büyük hesapsal güç ve zaman gerektirir. Bununla birlikte hedef doğrulama ve hedef görüntünün piksel altı konumunu belirlemede yapılan kaba hatalar önemli ölçüde göz ardı edilebilir. Çünkü böyle ölçü hataları demet dengelemenin kaba hata testiyle belirlenip elimine edilebilmektedir. Dolayısıyla, bütün uygun hedef bölgeleri kabul edilirken, hedef olmayan bölgelerin 90-95\% oranında elimine eden hızlı doğrulama metotlarını tasarlamak yeterlidir.

Hedef tanıma kriteri olarak çapraz korelasyon yöntemini kullanan yazılımda minimum korelasyon katsayısı için yüksek bir değer (> $0.80)$ girilirse hedef olmayan bölgelerin hedef bölgesi gibi tanınması çok sınırlı sayıda olacaktır. Fakat korelasyon katsayısı için düşük değerler girilmesi durumunda ek kriterler gerekli olur.

Yazılımda iki test kriteri kullanılmıştır. Bunlardan ilki, minimum değerin altında, maksimum değerin üstündeki hedefleri ret eden boyut aralığ 1 kriteridir. $\mathrm{Bu}$ yolla parlak alan bölgeleri ve yansıyan küçük 1şık benekleri elimine edilebilmektedir. İkinci test kriteri olarak ise, doğrultulardan biri için tarama satır 
eksenini kullanan iki dik doğrultudaki uzunlukların oranı kullanılmıştır.

\subsubsection{Hedef Görüntünün Piksel Altı Doğrulukta Ölçümü}

Hedef görüntünün geçerli görüntü üzerindeki konumunu piksel altı doğrulukta belirleyebilmek için farklı yöntemler kullanılabilir. Fakat yoğunluk ağırlıklı merkez belirleme metodu basit, hızlı ve doğru bir hesap yöntemi olması nedeniyle endüstriyel fotogrametri uygulamalarında en çok kullanılan yaklaşım olmuştur. Geliştirilen yazılımda da kullanılan bu yöntemde $\mathrm{x} 0$, y0 piksel altı ağırlık merkezi koordinatları;

$\left[\begin{array}{l}\mathrm{x}_{0} \\ \mathrm{y}_{0}\end{array}\right]=\frac{\sum_{i=1}^{n} \sum_{j=1}^{m} g_{i j}\left[\begin{array}{l}x_{i j} \\ y_{i j}\end{array}\right]}{\sum_{i=1}^{n} \sum_{j=1}^{m} g_{i j}}$

eşitliği ile hesaplanır. Burada, xij ve yij hedef görüntünün içerisindeki piksellerin satır ve sütun koordinatlarını, gij'de karşılık gelen gri değeri gösterir (Otepka ve diğ. 2002). Yüksek konrastlı görüntülerde bu teknik kullanılarak, piksel boyutunun \%2'sine varan bir ölçü doğruluğuna ulaşılabilmektedir (Fraser 1997).

Hedef görüntünün geçerli görüntü üzerindeki konumu piksel altı doğrulukta belirlendikten sonra bu değerler kullanılan algoritma gereği eşik değer belirlenmesinde kullanılan hedef görüntü merkezinin piksel koordinatları ile karşılaştırılır. Koordinat farkları 0.5 pikselden küçükse hesaplanan piksel altı koordinatlar doğru kabul edilir.

Koordinat farklarından birinin ya da her ikisinin 0.5 pikselden büyük olması durumunda ise hedef görüntü merkezinin yeni piksel koordinatları piksel altı koordinatların tam değerlere yuvarlanmasıyla elde edilir. $\mathrm{Bu}$ değerleri merkez alan hesap penceresi görüntüsünün kenar pikselleri kullanılarak eşik değer hesabı ve dolayısıyla eşikleme işlemi, doğrulama, geometrik testler ve hedef görüntünün geçerli görüntü üzerindeki piksel altı doğruluktaki konum hesabı tekrarlanır.

Son ișlem aşaması, her bir hedef görüntüsünün geçerli görüntü üzerindeki piksel alt1 konumunun resim koordinat sistemine dönüştürülerek resim koordinat dosyasına kayıt edilmesidir. Şekil 5, örnek bir uygulamada tanımlı hedef görüntüyü arama işlemi sonucu piksel altı konumları belirlenen noktaların yazılım görüntüsünü verir.

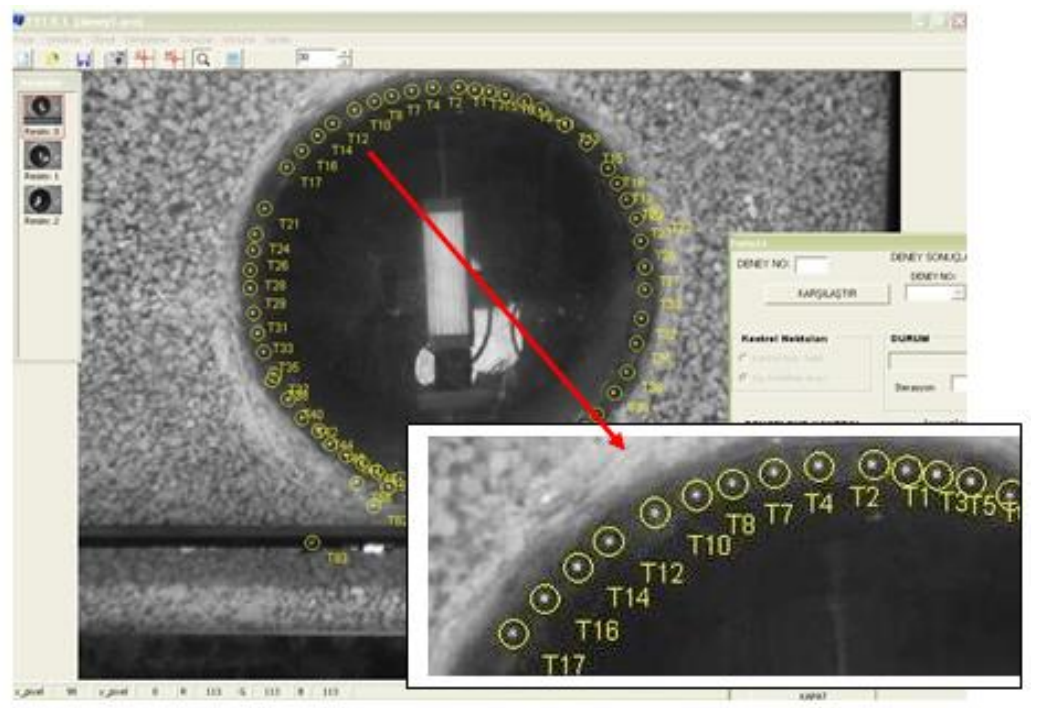

Şekil 5. Tarama işlemi sonrası yazılım görüntüsü 


\subsection{Görüntü Eşleme - Karşılıklı Görüntü Noktalarını Belirleme}

Başlangıç ölçme işleminde ikinci veri işleme adımı, görüntüler üzerinde karşılıklı görüntü noktalarının belirlenmesidir. Bu amaçla Furnea (1997) ve Sabel (1999) tarafindan önerilen epipolar plan açı yöntemi kullanılmıştır. Bu yöntem hizlıdır ve dijital kameralar kullanıldığı zaman eşlenik noktaların belirlenmesinde oldukça etkili olan mercek distorsiyonlarını da hesaba katar.

Epipolar plan açıları yönteminin esası, karşılıklı görüntü noktaları 1şınlarının herhangi bir epipolar düzlemle aynı açıları oluşturması ilkesine dayanır (Sabel 1999; Otepka ve diğ. 2002; Otepka 2001). İki resim için çözüm şekil 6 'da gösterilmiştir. Epipolar düzlemler daima her iki kamera istasyonunun izdüşüm merkezlerini içerir. Her iki görüntünün görüntü noktaları için gerekli açıları hesaplamak için ilk olarak keyfi bir epipolar düzlem tanımlanır.
Daha sonra uygulanan kısitlamalar yardımıyla normalize vektörler n1 ve n2 hesaplanır. Söz konusu kisitlamalar, her iki vektör ve baz doğrusunun bir birine dik olması ve $n 1$ 'in tanımlanan epipolar düzlem tarafindan içerilmesi koşullarıdır. Her iki görüntüdeki her bir görüntü noktası için epipolar düzlem açıları ise aşağıdaki eșitlik kullanılarak hesaplanır.

$\overline{r_{i}}=R\left[\begin{array}{c}x_{i} \\ y_{i} \\ -c\end{array}\right]$

$\theta=\arctan \left(\bar{n}_{2} \cdot \bar{r}_{i}, \bar{n}_{1} \cdot \bar{r}_{i}\right)$

Burada, R, geçerli görüntü için dönüklük matrisini, $\quad x_{i}$ ve $y_{i}$, görüntü noktasının düzeltilmiş resim koordinatlarını, c de kullanılan kameranın asal uzaklığını gösterir.

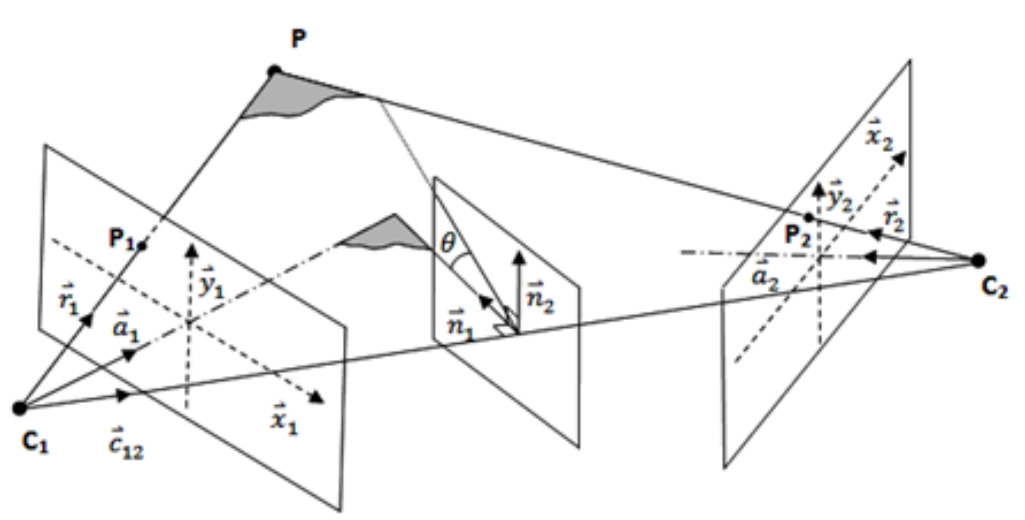

Şekil 6: Epipolar plan açı geometrisi

Epipolar düzlem açıları belirlendikten sonra, yazılımın eşleme parametrelerinde (Şekil 7) tanımlanan bir tolerans içinde aynı açısına sahip olacaklarından eşlenik görüntü noktaları kolayca belirlenebilir.

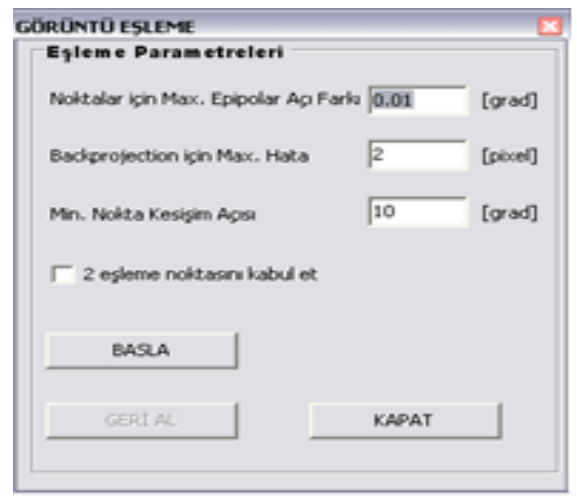

Şekil 7. Eşleme parametreleri 
Sonraki aşama, 3B uzayda iki doğrunun kesişim noktası olarak eşlenik görüntü noktalarının cisim nokta koordinatlarının hesaplanmasıdır. Yazılımın eşleme parametrelerinde tanımlanan minimum nokta kesişim açısı şartını sağlayan cisim noktaları, kolinearite eşitlikleri kullanılarak üçüncü resim üzerine izdüşürülür. İzdüşürülen nokta yine tanımlanan bir tolerans içinde var olan bir görüntü noktası ile çakışırsa, üçüncü nokta da belirlenmiş olur. Geriye izdüşüm işleminde doğru görüntü nokta konumlarını elde etmek için mercek distorsiyonları dikkate alınır. Resim çiftinin karşılıklı noktaları eşlendikten sonra sırayla bütün resim çifti kombinasyonları kullanılır. Yeni resim çiftlerinde yalnız atanmamış resim noktaları için epipolar plan açıları hesaplanır.

Bir görüntü noktası, ikinci görüntüde aynı epipolar plan açısına sahip birden fazla sayıda eşlenik noktaya sahip olabilir. Böyle durumlarda, ikinci resimde olası eşlenik noktaların her biri için cisim noktaları hesaplanır ve bu noktalar üçüncü resim üzerine izdüşürülür. $\mathrm{Bu}$ izdüşürülen noktalardan biri var olan resim noktalarından biri ile çakışırsa, eşleme belirsizliği çözülmüş olur.

\subsection{Uzaysal İleriden Kestirme Dengelemesi}

Başlangıç ölçme işleminde son adım, eşlenmiş noktaların 3B cisim koordinatlarının kalibrasyon işlemi sonuçları kullanılarak uzaysal ileriden kestirme dengelemesiyle belirlenmesidir. Cisim ve resim uzay 1 arasındaki perspektif dönüşümü tanımlayan matematik model burada da geçerlidir.

Uzaysal ileriden kestirme problemi en küçük kareler kestirimi ile çözülebilir. Bu durumda, ölçüler, farklı görüntülerdeki karşılıklı noktaların resim koordinatları, bilinmeyenlerde bu noktaların cisim uzay koordinatları olur.

\subsection{Online Fotogrametrik İşlem Aşaması}

Kalibrasyon parametreleriyle yöneltme bilinmeyenlerinin belirlendiği sistem kalibrasyonu ve başlangıç ölçmesini içeren fotogrametrik işlem aşamasından sonra yük altındaki yapı elemanı üzerindeki işaretli hedef noktaların izlenmesi yani online fotogrametrik işlem aşamasına geçilebilir. Online fotogrametrik işlem aşaması kısaca,

- Yük testi süresince istenen zaman aralıklarında otomatik olarak ya da her yüklemeden sonra kullanıcı müdahalesiyle test malzemesinin görüntülerinin alınması,

- Başlangıç ölçmesinde karşılıklı olarak belirlenen hedef noktaların resim koordinatlarının yoğunluk ağırlıklı merkez belirleme metoduyla piksel altı doğrulukta otomatik olarak ölçülmesi,

- $\mathrm{Bu}$ noktaların üç boyutlu cisim koordinatlarının sabit kamera pozisyonlarından kalibrasyon parametreleri kullanılarak uzaysal ileriden kestirme dengelemesiyle belirlenmesi işlem adımlarından oluşur.

Yazılım tarafından geçerli ölçme oturumuna ait hedef görüntülerin piksel altı konumlarının belirlenmesinde bir önceki ölçme oturumuna ait aynı hedef noktaların piksel koordinatlarını merkez alan arama penceresi kullanılır.

Bir ölçme uygulamasında ölçme oturumlarına ait uzaysal ileriden kestirme dengeleme kontrol parametreleri dengeleme öncesi online uygulama diyalog penceresinde tanımlanır ve dengeleme sonrası dengeleme sonuçları yine bu diyalog penceresi üzerinde özet olarak gösterilir (Şekil 8). Dengeleme sonuçlarının ayrıntıl1 gösterimi ise bir metin dosyas1 biçiminde yazılım tarafından otomatik olarak oluşturulan online klasörü içerisine yazdırılmaktadır. 


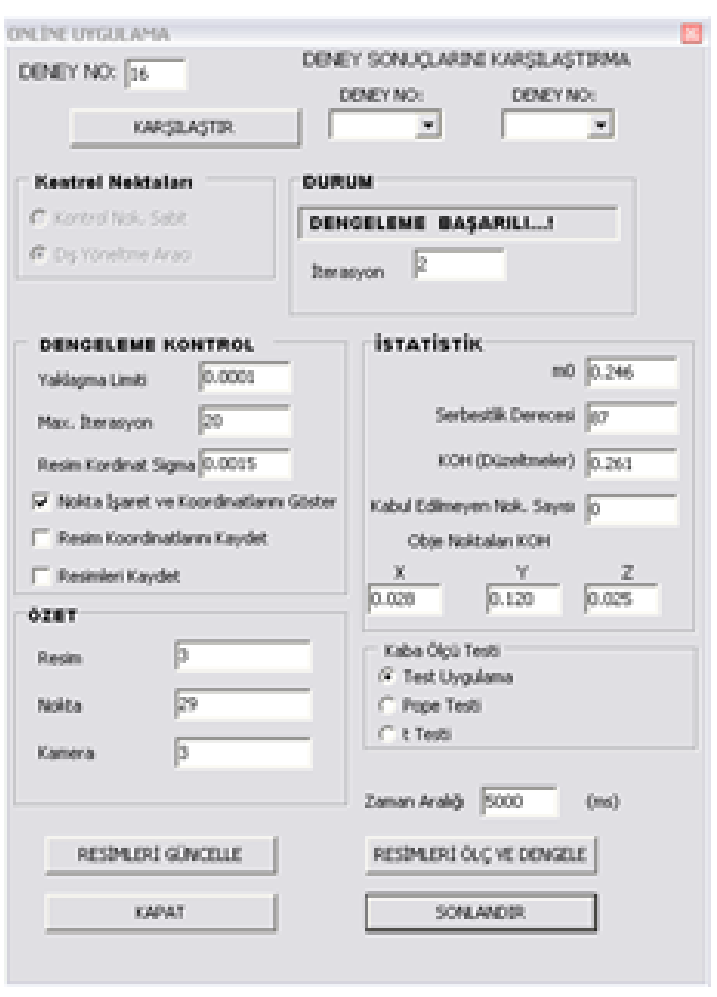

Şekil 8. Yazılımın online uygulama diyalog penceresi

\section{4. İNŞAAT MÜHENDİSLİĞİNDE ÖRNEK UYGULAMALAR}

Geliştirilen sistemin test edilmesi amacıyla gömülü esnek borularla, çelik kirişin statik yük testi deneyleri olmak üzere iki farklı uygulama yapılmıştır.

\subsection{Gömülü Esnek Boruların Yük Testi Deneyleri}

Yıldız Teknik üniversitesi, İnşaat Mühendisliği Bölümü, Geoteknik Anabilim Dalı laboratuvarında gerçekleştirilen bir diğer çalışma gömülü esnek boruların yük altındaki davranışları üzerine olmuştur. Deneylerde klasik ölçme aracı doğrusal değişimli fark transformatörleri ile fotogrametrik sistem birlikte kullanılmış ve ölçme sonuçları karşılaştırılmıştır.

İçine esnek boruların yerleştirildiği deney kutusunun boyutları 500x700 mm'dir (Şekil 9). Fotogrametrik ölçmeler yapılabilmesi için kutunun ön yüzüne $20 \mathrm{~mm}$ kalınlığında pleksiglas cam yerleştirilmiştir. Yükleme için hava basıncı ile çalışan membran yastıklar kullanılmış ve kutu kapağı ve iki yan duvarında bu yastıklarla yüklemelerin yapılabilmesi için delikler açılarak farklı yükleme biçimlerinin uygulanabilmesi sağlanmıştır. Deneyler, üç farklı çapta boru (110 mm, $242 \mathrm{~mm}$ ve $312 \mathrm{~mm}$ ) ve kum ve çakıldan oluşan iki farklı zemin malzemesi üzerine olmuştur.

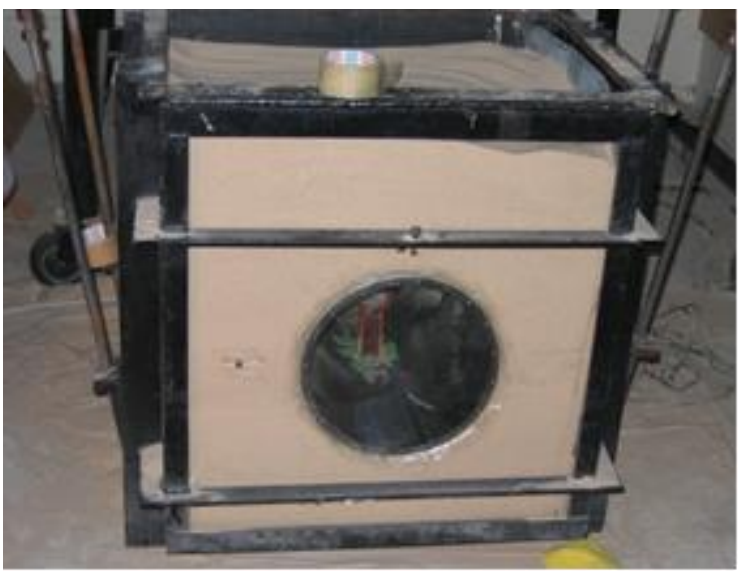

Şekil 9. Deney kutusu ve esnek boru

Deneylerde, genellikle borunun içerisine yaklaşık düşey konumda borunun çapını gösterecek biçimde yerleştirilen LVDT de kullanılmıș ve aşamalı yüklemeler altında LVDT ölçme okumaları yapılarak eş zamanlı olarak bilgisayar üzerinde bir metin dosyaya kaydedilmiştir. Fotogrametrik sistemle elde edilen ölçme değerleri LVDT okumalarının da

yapıldığı yükleme sonrası kullanıcı müdahalesiyle elde edilmiştir. Fotogrametrik değerlendirmelerde kamera objektifine girmeden önce hava ve cam gibi farklı ortamlardan geçen 1ş1k 1şınlarının kırılmalarının neden olduğu görüntü distorsiyonları kolinearite eşitliliklerinde modellenmiştir. Görüntülerin elde edildiği kamera düzenlemesiyle ilgili bilgiler Tablo 1 'de verilmiştir. 
Tablo 1. Görüntü elde etmede kullanılan kamera düzenlemesi

\begin{tabular}{lllll}
\hline $\begin{array}{l}\text { Deney } \\
\text { grubu }\end{array}$ & $\begin{array}{c}\text { Mesafe } \\
\text { (Kenar } \\
\text { Kameralar) } \\
(\mathbf{c m})\end{array}$ & $\begin{array}{c}\text { Resim } \\
\text { ölçeği }\end{array}$ & $\begin{array}{c}\text { Mesafe } \\
\text { (orta } \\
\text { kamera) } \\
\text { (cm) }\end{array}$ & $\begin{array}{c}\text { Resim } \\
\text { ölçeği }\end{array}$ \\
\hline $\mathbf{3 1 2} \mathbf{~ m m}$ & 135 & $1: 85$ & 125 & $1: 100$ \\
\hline $\mathbf{2 4 2} \mathbf{~ m m}$ & 125 & $1: 75$ & 110 & $1: 85$ \\
\hline $\mathbf{1 1 0} \mathbf{~ m m}$ & 95 & $1: 60$ & 85 & $1: 60$ \\
\hline
\end{tabular}

Toplam 27 adet deney ve deneylerde her biri $10 \mathrm{kPa}$ 'lı en az 9 yükleme yapılmıştır. Boruların yük altındaki davranışlarının belirlenmesi amaciyla düşey yönde yapılan LVDT ölçme okumalarıla, fotogrametrik sistemin ölçme sonuçları karşılaştırılmıştır. Şekil 10, $242 \mathrm{~mm}$ çaplı esnek boruya ait ölçme sonuçlarının kıyaslamasının gösterir. Benzer grafikler farkl1 zemin malzemelerinin kullanıldığı üç farklı çaptaki borunun bütün yük testi deneyleri için elde edilmiştir.

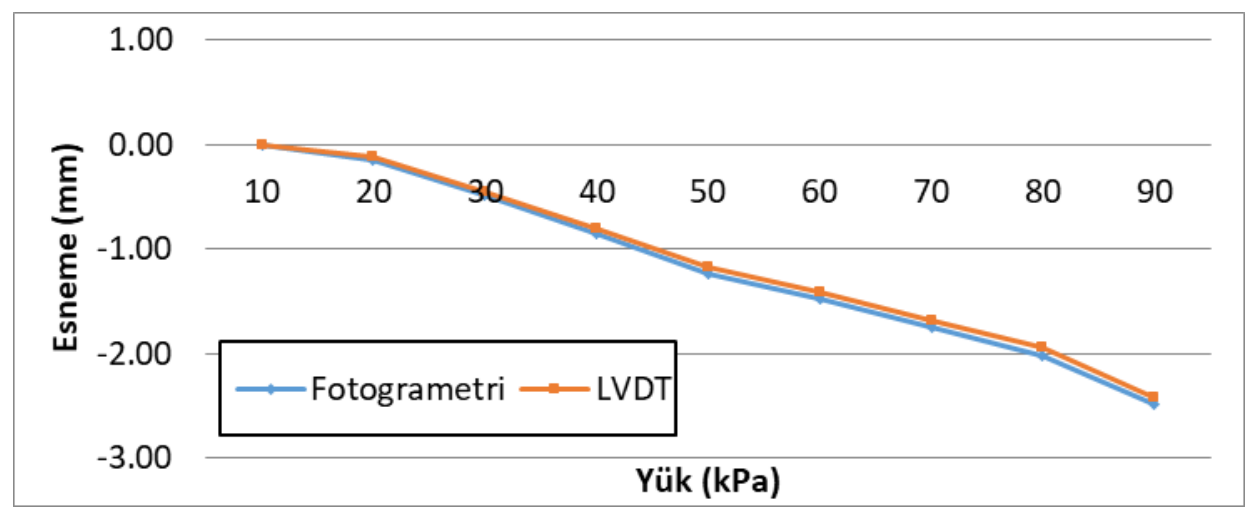

Şekil 10. $242 \mathrm{~mm}$ çaplı esnek boru için ölçme sonuçlarının karşıllaştırılması

Düşey yük altında kalan gömülü esnek borular, neredeyse eşit değerlerde düşey eksende kısalma ve yanal eksende uzama biçiminde ovalleșerek şekil değiștirmektedir. Fotogrametrik değerlendirmelerde, üç farklı çaptaki borunun bütün yük testi deneylerinde, her bir ölçme oturumu için resim koordinat düzeltmelerinin karesel ortalama hata değerleri, 0.02 pikselle 0.06 piksel aralığında elde edilmiştir.

312 ve $242 \mathrm{~mm}$ çaplı esnek boruların deneylerinde, yine her bir ölçme oturumu için cisim nokta koordinatlarının ortalama prezisyon değerleri, $X$ doğrultusunda 20-39 $\mu \mathrm{m}, \quad \mathrm{Y}$ doğrultusunda $96-222 \mu \mathrm{m}$ ve $\mathrm{Z}$ doğrultusunda da 21-66 $\mu \mathrm{m}$ aralığında hesaplanmıştır. $110 \mathrm{~mm}$ çaplı esnek borunun yük testi deneylerindeyse, ölçme oturumları için cisim nokta koordinatlarının ortalama prezisyon değerleri, $X$ ve $Z$ doğrultularında 13$24 \mu \mathrm{m}, \mathrm{Y}$ doğrultusunda da 66-106 $\mu \mathrm{m}$ aralığında hesaplanmıştır.
Esnek boruların yük testi deneylerinde, özellikle koordinat sisteminin Y koordinat bileşenindeki ortalama prezisyon değerleri, sistemden beklenen değerlere göre daha kaba çıkmıştır. Bu sonuca, deney kutusu içerisinde kullanılan zemin malzemesinin yükleme testleri boyunca pleksiglas camı çizmesi ve görüntü kalitesinin camdan etkilenmesi ve pleksiglas camın kırılma indisinin bütün cam yüzeyi boyunca homojen olmaması gibi olumsuz etkilerin sebep olduğu düşünülmektedir.

\section{2. Çelik Kirişin Yük Testleri}

İstanbul Teknik üniversitesi, İnşaat Mühendisliği Bölümü, Yapı Anabilim Dalı laboratuvarında gerçekleştirilen son çalışma ise yaklaşık $2.40 \mathrm{~m}$ boyutlarında çelik bir kirişin yaklaşık orta bölümünün yük altındaki davranışlarının belirlenmesi üzerine olmuştur. Kirişin bu bölümünde, yaklaşık $6 \mathrm{~cm}$ aralıklı 7 
hedef noktası kullanılmış ve toplam 3 deney yapılmıştır.

Görüntü alma ekseni yönündeki koordinat bileşeni Y ekseni olacak şekilde yerleştirilen test alanı kullanılarak yapilan sistem kalibrasyonundan sonra 5 farklı ağırlık sırayla kiriş üzerine yerleştirilmiş ve her yük uygulamasından sonrada fotogrametrik sistemle ölçmeler gerçekleştirilmiştir. Deneylerde, kenarlardaki kameraların çelik kirișe olan mesafeleri yaklașık $110 \mathrm{~cm}$ (görüntü ölçeği 1:70), ortadaki kameranınsa yaklaşık $105 \mathrm{~cm}$ (görüntü ölçeği 1:60) olacak biçimde bir kamera düzenlemesiyle görüntüler elde edilmiştir. Çelik kiriş üzerine yapıştırılan hedef noktaların ikinci yükleme deneyine ait düşey yöndeki yer değiştirmelerinin yüke bağl1 değişimleri Şekil 11'de gösterilmiştir. Bu deneyde, en son yerleştirilen ağırlık ilk kaldırılan ağırlık olacak biçimde bir sıralamayla ağırlıklar kaldırılarak tersine bir yükleme daha uygulanmıştır.
Resim koordinat düzeltmelerinin karesel ortalama hata değerleri, tüm ölçme oturumları için 0.03 pikselle 0.04 piksel aralığında elde edilmiştir. Her bir deneye ait ölçme oturumları için hesaplanan cisim nokta koordinatlarının ortalama prezisyon değerleriyse XZ koordinat bileşenleri için 0.019-0.021 um aralığında, Y koordinat bileşeni içinde 0.069-0.076 um aralığında hesaplanmıştır.

Fotogrametrik sistemin test edilmesi amaciyla birinci deneyde klasik deformasyon ölçme aleti ekstansometre de kullanılmış ve söz konusu aletle çelik kirişin yaklaşık orta noktasının düşey yönlü yer değiştirmesi $2.90 \mathrm{~mm}$ olarak ölçülürken fotogrametrik sistemle yine ayn1 konumdaki hedef noktasının yer değiştirmesi $2.87 \mathrm{~mm}$ olarak ölçülmüştür. Üç deneyde de hedef noktalarının tümünün düşey yönlü hareketleri neredeyse birbirlerine eşit değerlerde elde edilmiştir.

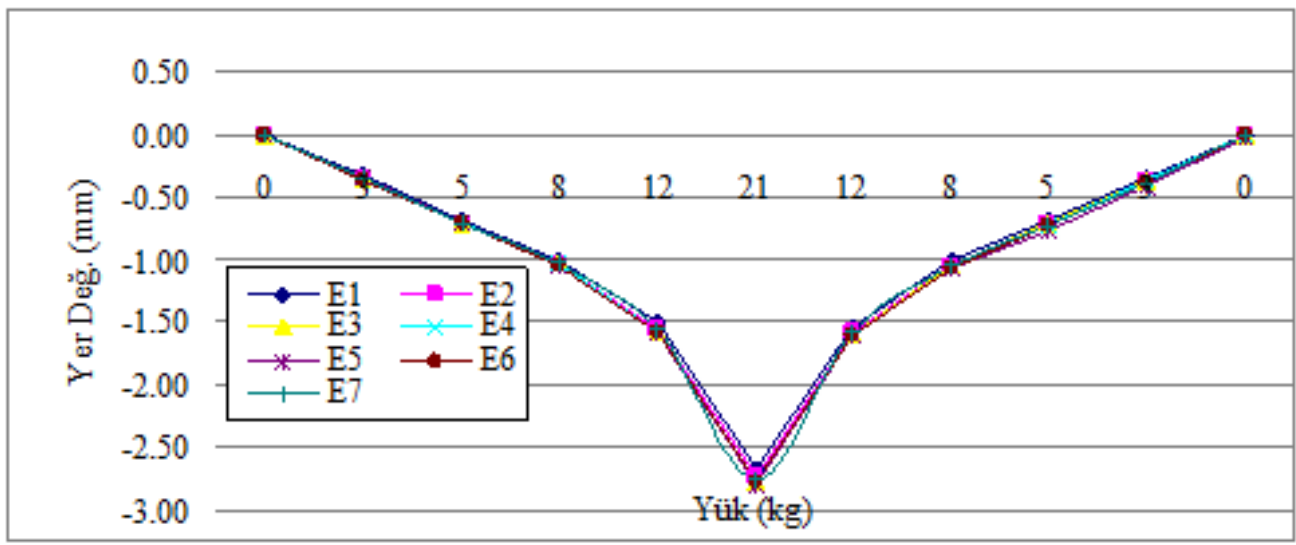

Şekil 11: Fotogrametrik olarak ölçülen yük yer değiştirme davranış1

\section{SONUÇLAR}

Çalışmada, yük testleri süresince konumsal yer değiştirmeye konu olan hedef noktaların fotogrametrik teknikler yardımıyla otomatik olarak ölçülmesi ve izlenmesi için geliştirilen sistem ve kullanılan yöntemler sunulmuştur. Görüntülerin elde edilmesinden üç boyutlu cisim koordinatlarının hesabına kadar bütün işlem aşamaları geliştirilen sistem içerisinde çözümlenebilmektedir.

Sistemin işlevselliğini göstermek için iki farklı uygulama yapılmıştır. Bunlar, gömülü esnek borularla çelik kirişin statik yük testi deneyleridir. Fotogrametrik sistemle, bu deneylerin her bir ölçme oturumu için $\mathrm{mm}$ düzeyi altında cisim nokta prezisyonları elde edilmiştir. Geliştirilen fotogrametrik sistemle LVDT'den elde edilen ölçme sonuçları kıyaslanmış ve fotogrametrik sistemin, inşaat mühendisliği malzeme testi uygulamaları için doğru ve güvenilir bir ölçme sistemi olduğu gösterilmiştir.

Deneylerde, sistem kalibrasyonu ve başlangıç ölçmesinden sonra yük altındaki yapı elemanının görüntülerin elde edilmesi, ișaretli hedef noktaların resim koordinatlarının ölçmesi ve bu noktaların üç boyutlu cisim koordinatları hesabı işlemini içeren online 
fotogrametrik işlem aşaması gerçek zamana yakın (0.4- 0.9 sn) çözümlenebilmiştir.

Sistem bundan sonra yapılacak çalışmalarda hem yazılım hem donanım açısından geliştirilmeye uygundur. Ölçülecek cismin boyutuna bağlı olarak istenen görüntü derinliğinin sağlanabilmesi için farklı odak uzaklığa sahip mercekler ya da farklı kameralar sistemde kullanılabilir veya sisteme eklenebilir.

\section{KAYNAKÇA}

Maas, H.-G. and Hampel, U., (2006). Photogrammetric Techniques in Civil Engineering Material Testing and Structure Monitoring, Photogrammetric Engineering and Remote Sensing, Vol. 72, No. 1, 39-45.

Hampel, U. and Maas, H.-G., (2003). Application of digital photogrammetry for measuring deformation and cracks during load tests in civil engineering material testing, 6th Conference on Optical 3-D Measurement Techniques, Swiss Federal Institute of Technology, Zürich, 22-25.9., Vol. II, pp. 80-88.

Whiteman, T., D. and Lichti, D.D., (2002). Measurement of deflections in concrete beams by close range photogrammetry, ISPRS Commission IV Symposium, Geospatial Theory, Processing and Applications, International Archives of Photogrammetry and Remote Sensing, Volume XXXIV, Part 4.

Woodhouse, N.G., Robson, S. and Eyre, J., (1999). Vision metrology and three dimensional visualization in structural testing and monitoring, Photogrammetric Record, XVI (94), 625-642. ISSN: 0031-868X.

Valença, E. Júlio, H. Araújo, (2012). Application of photogrammetry to structural assessment, Experimental Techniques, Wiley 36.

Fraser C.S., and Riedel B., (2000). Monitoring the thermal deformation of steel beams via vision metrology, ISPRS ISPRS Journal of Photogrammetry and Remote Sensing, 55, pp.268-276.

Mills, J. P., Newton, I. and Peirson, G. C., (2001). Pavement deformation monitoring in a rolling load facility, Photogrammetric Record, 17(97), 7-24.
Fraser, C.S., (1997). Digital camera self-calibration, ISPRS Journal of Photogrammetry and Remote Sensing, Vol. 52, pp. 149-159.

Kraus, K., (1997). Photogrammetry, vols 1, Bonn, Dümmler, ISBN 3-427-78686-6, 78653-6.

Shortis, M.R., Clarke, T.A. \& Short, T., (1994). Comparison of some techniques for the subpixel location of discrete target images, SPIE Proceedings, Vol. 2350, P. 25.

Sabel, J.C, (1999). Calibration and 3D Reconstruction for Multi Camera Marker Based Motion Measurement, PhD thesis, Faculty of Applied Physics, Technical University of Delft, Netherlands.

Otepka, J., (2001). Algorithms and their implementation in an automated closerange photogrammetric system, Diploma thesis, Vienna University of Technology.

Otepka, J.O., Hanley, H.B., and Fraser, C.S., (2002). Algorithm developments for automated offline vision metrology, Proceedings of the ISPRS Commission V Symposium, ISPRS, Corfu, Greece, September, 1-2, pp. 60-67. 